\title{
COVID Face Masks and the Wuhan Lab Escape Theory: An Update
}

\author{
Colin A. Ross*
}

Institute for Psychological Trauma, 1701 Gateway, Suite 349, Richardson, TX 75080, USA

*Corresponding author: Colin A. Ross, Institute for Psychological Trauma, 1701 Gateway, Suite 349, Richardson, TX 75080, USA

Received: May 31, 2021; Accepted: June 09, 2021; Published: June 18, 2021

\section{Developments Concerning the Wuhan Lab Leak Theory}

Only a few months ago, a commentary, with supporting evidence, and a supporting quotation from the former head of the CDC, that the Wuhan lab leak theory for the origin of the COVID-19 epidemic "is a rational, reasonable, and scientifically grounded theory" could have been characterized as a conspiracy theory [1]. Now, a few months later, the Wuhan lab leak theory is being acknowledged widely in the mainstream media as just that - rational, reasonable, and scientifically grounded [2,3]. The fact that Chinese military experiments have been conducted at the Wuhan Institute of Virology has recently been confirmed by Mike Pompeo, a former US Secretary of State and former Director of the CIA [3], and is stated on a US Government website [4]: "Despite the WIV presenting itself as a civilian institution, the United States has determined that the WIV has collaborated on publications and secret projects with China's military. The WIV has engaged in classified research, including laboratory animal experiments, on behalf of the Chinese military since at least 2017." https://ge.usembassy.gov/ fact-sheet-activity-at-the-wuhan-institute-of-virology/

A few months ago, such a statement would have been dismissed as a conspiracy theory. The mainstream media is now pointing out that gain of function research on coronaviruses at the Wuhan Institute of Virology was funded by the NIH and NIAID [2,3]. In 2015, researchers from the United States and the Wuhan Institute of Virology published a paper in a medical journal stating that gain of function research at the Wuhan Institute of Virology was funded by the NIH and NIAID [5]. Several quotations from this paper confirm this fact: "In addition to offering preparation against future emerging viruses, this approach must be considered in the context of the US government-mandated pause on gain-of-function (GOF) studies. (p. 1512) On the basis of these findings, scientific review panels may deem similar studies building chimeric viruses based on circulating strains too risky to pursue, as increased pathogenicity in mammalian models cannot be excluded. ( $p$ 1512) In developing policies moving forward, it is important to consider the value of the data generated by these studies and whether these types of chimeric virus studies warrant further investigation versus the inherent risks involved. (p. 1513)"

The paper describes the contributions to this gain of function research by coauthor Xing-Ye Ge at the Wuhan Institute of Virology. Despite this paper being published in 2015, until recently anyone claiming that the NIH and NIAID funded gain of function research on coronaviruses at the Wuhan Institute of Virology would have been dismissed as a conspiracy nut, and likely as a racist xenophobe. In a February, 2021 article [6], Dr Peter Ben Embarek, speaking as a member of the WHO investigation team on the origins of the COVID-19 pandemic, was quoted as dismissing the Wuhan lab leak theory. Dr. Embarek is the President of Eco Health Alliance which acted as a conduit for the NIH and NIAID funding of coronavirus gain of function research at the Wuhan Institute of Virology [2]. Funding of this research by Eco Health Alliance is acknowledged by the authors of the 2015 paper reporting that research [7].

Former US Secretary of State and Director of the CIA, Mike Pompeo was quoted as saying in a May 25, 2021 [8] article that: "It was outrageous to see scientists, even government, U.S. government scientists who were denying this when they surely must have seen the same information that I had seen," Pompeo said. "That includes certainly Dr. Fauci as well." https://www.foxnews.com/politics/pompeo-outrageous-faucilab-leak-theory. Dr. Fauci has been denying that NIAID funded gain of function research at the Wuhan Institute of Virology. He and Dr. Francis Collins, Director of the NIH both denied this in recent testimony to the US House Appropriations Committee. A video of Dr. Fauci making this denial is available along with a May 25, 2021 article on the topic [5]. There are only two possible explanations for Dr. Fauci's denial of $\mathrm{NIH}$ and NIAID funding of coronavirus gain of function research at the Wuhan Institute of Virology: 1) he is not telling the truth, or 2) he has no idea what is going on at NIAID. Gain of function research means modifying viruses to make them more infectious and more deadly. Need we ask why the Chinese military has been funding research at the same lab in the same time period? The United States government has funded such research at the Wuhan Institute of Virology, so the US should not be pointing a finger at China.

It is an important question whether the COVID-19 pandemic originated due to the virus jumping from bats to humans in the wild or from a leak at the Wuhan Institute of Virology. However, it is more important to investigate the disinformation originating from medical leadership in the United States and the discrediting of anyone who questions government public health policies concerning COVID-19 - the discrediting is done with charges of being antiscientific, a conspiracy nut, a racist, and a xenophobe. Curiously, but not surprisingly, the charge of anti-science is often brought against 'conspiracy nuts' by people who themselves are anti-scientific. 
Things are changing, however. A May 28, 2021 article [9] discusses a paper in press at Quarterly Reviews of Biophysics Discovery [10] that provides compelling evidence that the COVID-19 virus was engineered at the Wuhan Institute of Virology as part of gain of function research conducted there. According to the author of the May 28 article, this research by Sorensen, Susrud and Dalgleish, who have previously published in the same journal [11], was rejected by a number of journals before finally being published. The May 28 article states that: [Sorensen, Susrud and Dalgleish] said they tried to publish their findings but were rejected by major scientific journals which were at the time resolute that the virus jumped naturally from bats or other animals to humans.

Even when former MI6 chief Sir Richard Dearlove spoke out publicly saying the scientists' theory should be investigated, the idea was dismissed as 'fake news.' Over a year later, leading academics, politicians and the media finally flipped, and have begun to contemplate the possibility that COVID-19 escaped from the Wuhan Institute of Virology in China - a lab where experiments included manipulating viruses to increase their infectiousness in order to study their potential effects on humans. Soon, hopefully, physicians and researchers will no longer be blackballed for taking the Wuhan lab leak theory seriously.

\section{Licensing Body Sanctions against Physicians Who Question Public Health Policies about Face Masks}

We are now moving into a phase of the COVID-19 pandemic in which centralized government and regulatory bodies are threatening physicians with sanctions if they question public health policies concerning face masks for COVID-19 protection. The College of Physicians and Surgeons of Ontario recently issued a Statement concerning COVID-19 [12]: "The College is aware and concerned about the increase of misinformation circulating on social media and other platforms regarding physicians who are publicly contradicting public health orders and recommendations. Physicians hold a unique position of trust with the public and have a professional responsibility to not communicate anti-vaccine, anti-masking, anti-distancing and anti-lockdown statements and/or promoting unsupported, unproven treatments for COVID-19. Physicians must not make comments or provide advice that encourages the public to act contrary to public health orders and recommendations. Physicians who put the public at risk may face an investigation by the CPSO and disciplinary action, when warranted. When offering opinions, physicians must be guided by the law, regulatory standards, and the code of ethics and professional conduct. The information shared must not be misleading or deceptive and must be supported by available evidence and science."

It is a scientifically proven fact that face masks have no effect on the transmission of viruses in public and no effect on rates of disease [13-16]. This fact is based on multiple randomized controlled trials and meta-analyses. Any Ontario physician who tells patients this scientific fact is now in danger of being censored and sanctioned by the Ontario College of Physicians and Surgeons of Ontario. Perhaps, in another year, leading physicians will be stating that mandating of face masks was a well-intentioned social control tactic but is not supported by science. Perhaps medical authorities will be citing nonexistent 'newly emerging data' as a justification for no longer requiring face masks in public, even for unvaccinated persons. Or perhaps not. Perhaps we will be stuck with a pandemic of iatrogenic anxiety based on fears about no longer wearing face masks.

A concluding question: what is the difference between a conspiracy theory and the truth? Answer: 6-12 months.

\section{References}

1. Ross CA (2021) Misinformation concerning face masks and the Wuhan lab leak. Journal of Neurology Neurocritical Care 4: 1-3.

2. Knapton A (2021) Why the Covid Wuhan lab escape theory, dead and buried months ago, has risen again. https://www.yahoo.com/news/why-covid-wuhan-labescape-152301731.html.

3. Shaw A (2021) Pompeo says Wuhan lab was engages in military activity alongside civilian research. https://www.yahoo.com/news/pompeo-says-wuhan-labengaged-154413535.html.

4. https://ge.usembassy.gov/fact-sheet-activity-at-the-wuhan-institute-of-virology/

5. Chamberlain S (2021) Fauci admits 'modest' NIH funding of Wuhan lab but denies 'gain of function'. https://nypost.com/2021/05/25/fauci-admits-nih-funding-ofwuhan-lab-denies-gain-of-function/.

6. Newey S (2021) Expert from WHO origins investigation warns against relying -too much on US intel' on COVID-19. https://www.telegraph.co.uk/global-health/ science-and-disease/expert-origins-investigation-warns-against-relying-much-usintel/

7. Menachery VD, Yount BL Jr, Debbink K, Agnihothram S, Gralinski LE, et al. (2015) A SARS-like cluster of circulating bat coronaviruses shows potential for human emergence. Nature Medicine 21: 1508-1513. [crossref]

8. Olson T (2021) Pompeo says it's 'outrageous' US officials, including Fauci, dismissed lab leak theory. https://www.foxnews.com/politics/pompeo-outrageous-fauci-lableak-theory.

9. Boswell J (2021) Covid-19 'has NO credible natural ancestor' and WAS created by Chinese scientists who then tried to cover their tracks with 'retro-engineering' to make it seem like it naturally arose from bats, explosive new study claims. https:// www.dailymail.co.uk/news/article-9629563/Chinese-scientists-created-COVID-19lab-tried-cover-tracks-new-study-claims.html.

10. Sorensen B, Susrud A, Dalgleish AG (in press) A reconstructed aetiology of the SARS-Coronavirus-2 spike. Quarterly Reviews of Biophysics Discovery.

11. Sorensen B, Susrud A, Dalgleish AG (2020) Biovacc-19: A candidate vaccine for Covid-19 (SARS-CoV-2) developed from analysis of its general method of action for infectivity. Quarterly Reviews of Biophysics Discovery. doi: 10.1017/qrd.2020.8.

12. College of Physicians and Surgeons of Ontario. https://www.cpso.on.ca/News/KeyUpdates/Key-Updates/COVID-misinformation.

13. Ross CA (2020) Differences in evaluation of hydroxychloroquine and face masks for SARS-CoV-2. Journal of Neurology and Neurocritical Care 3: 1-3.

14. Ross CA (2020) Thoughts on COVID-19. Journal of Neurology and Neurocritical Care 3: $1-3$.

15. Ross CA (2020) Facemasks are not effective for preventing transmission of the coronavirus. Journal of Neurology and Neurocritical Care 3: 1-2.

16. Ross CA (2020) How misinformation that facemasks are effective for reducing COVID-19 is transmitted. Journal of Neurology Neurocritical Care 3: 1-2.

\section{Citation:}

